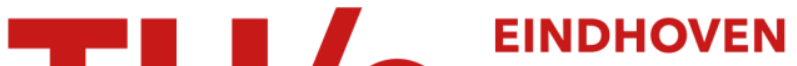

\section{Core research and innovation areas in cyber-physical systems of systems}

\section{Citation for published version (APA):}

Reniers, M. A., Engell, S., \& Thompson, H. (2015). Core research and innovation areas in cyber-physical systems of systems. ERCIM News, 102, 11-13.

\section{Document status and date:}

Published: 01/01/2015

\section{Document Version:}

Publisher's PDF, also known as Version of Record (includes final page, issue and volume numbers)

\section{Please check the document version of this publication:}

- A submitted manuscript is the version of the article upon submission and before peer-review. There can be important differences between the submitted version and the official published version of record. People interested in the research are advised to contact the author for the final version of the publication, or visit the $\mathrm{DOI}$ to the publisher's website.

- The final author version and the galley proof are versions of the publication after peer review.

- The final published version features the final layout of the paper including the volume, issue and page numbers.

Link to publication

\section{General rights}

Copyright and moral rights for the publications made accessible in the public portal are retained by the authors and/or other copyright owners and it is a condition of accessing publications that users recognise and abide by the legal requirements associated with these rights.

- Users may download and print one copy of any publication from the public portal for the purpose of private study or research.

- You may not further distribute the material or use it for any profit-making activity or commercial gain

- You may freely distribute the URL identifying the publication in the public portal.

If the publication is distributed under the terms of Article 25fa of the Dutch Copyright Act, indicated by the "Taverne" license above, please follow below link for the End User Agreement:

www.tue.nl/taverne

Take down policy

If you believe that this document breaches copyright please contact us at:

openaccess@tue.nl

providing details and we will investigate your claim. 
The 130 participations from 12 countries engaged $€ 270$ million, and have been awarded $€ 76$ million national and $€ 48$ million EU grants to position Europe as the leader in power electronics.

\section{Electric mobility}

European companies are world leaders in automotive innovation and sales. Together with their suppliers of electronic components and systems, they have proposed ambitious actions to establish leadership in electric mobility.

- E3Car: Nanoelectronics for an Energy Efficient Electrical Car (Jan 2009 - Jan 2012) achieved a breakthrough in nanoelectronic technologies, devices and miniaturised subsystems achiev-ing 35\% energy savings for the same performance.

- Pollux: Process Oriented Electrical Control Units for Electrical Vehicles Developed on a Multi-system Realtime Embedded Platform (Mar 2010 Feb 2013) generated the first platform concept for electric vehicles architecture, electronics, communication and embedded systems.

- IoE: Internet of Energy for Electric Mobility (May 2011 - Apr 2014) en- abled seamless connectivity and created middleware to achieve interoperability of the Internet applications addressing the electric mobility infrastructure.

- Motorbrain: Nanoelectronics for Electric Vehicle Intelligent Failsafe Powertrain (Apr 2011 - Mar 2014) introduced radical innovation in component and subsystems resulting in unparalleled energy efficiency of the drive-train and safe exit from traffic even in case of failure.

ECSEL JU is now launching a new research and innovation action, taking these concepts to the next level:

- 3CCAR: Integrated Components for Complexity Control in Affordable Electrified Cars (Apr 2015 - Apr 2018) shall introduce innovative approaches at all levels (vehicle architecture, sub-systems, components) to increase the affordability of the electric vehicles and accelerate their market penetration.

One hundred and fifty one participations from 16 countries engaged $€ 175$ million , and were awarded $€ 49$ million national and $€ 37$ million EU grants to defend Europe's leading position in the global competition.

\section{Conclusion}

The ECSEL JU three-way funding model (private sector, Member States and EU) is proven as compelling. It succeeds in leveraging significant private and public investments and concentrating them on strategic priorities. The ECSEL JU offers a fertile collaborative environment for large and small companies, academic and institutional researchers from all around Europe, together developing and implementing high impact industrial strategies, which are beneficial for Europe in general.

Link:

http://www.ecsel-ju.eu/

Please contact:

Andreas Wild, Executive Director of the ECSEL Joint Undertaking

E-mail: Alun.Foster@ecsel.europa.eu

\title{
Core Research and Innovation Areas in Cyber-Physical Systems of Systems
}

\author{
by Michel A. Reniers, Sebastian Engell and Haydn Thompson
}

\begin{abstract}
The CPSoS project (http://www.cpsos.eu) is developing a European roadmap for future research activities in Cyber-Physical Systems of Systems (CPSoS), which are large complex physical systems that interact with and are controlled by a considerable number of distributed and networked computing elements and human users [1]; see Figure 1. Examples include automotive systems [2], rail systems, electric grids, smart buildings, and large production facilities.
\end{abstract}

To date, research activities on CPSoS have largely been performed by individual domains, e.g. computer science, simulation technology and systems and control, with little cooperation and exchange between the different areas. To capture the views of industry and academia and from different communities, the CPSoS project has set up three working groups:

- Systems of Systems (SoS) in Transportation and Logistics,

- Physically Connected Systems of Systems,

- Tools for Systems of Systems Engineering and Management.
The working groups currently comprise 36 members, leading specialists from industry and academia, and include delegates from ongoing EU-funded projects in the area of SoS to ensure that as many views as possible are represented. Members of the working groups are listed at http://www.cpsos.eu.

By means of three industry/academia working groups, public workshops and consultations and interviews with over 100 practitioner experts in the field from large companies, mid-caps, SMEs and academia, the project has produced a comprehensive view of the state-ofthe-art in transport and logistics, elec- tric grids, smart buildings, industrial production systems and in supporting tools and techniques (see http://www. cpsos.eu/state-of-the-art/). The discussions in the working groups and the consultations have been summarized in a working paper on the core research and innovation areas (see http://www. cpsos.eu/roadmap/). Three key research topics, described below, have been identified:

\section{Challenge 1: Distributed, reliable} and efficient management of Cyber-Physical Systems of Systems Owing to the scope and complexity of $\mathrm{CPSoS}$ as well as the ownership or man- 


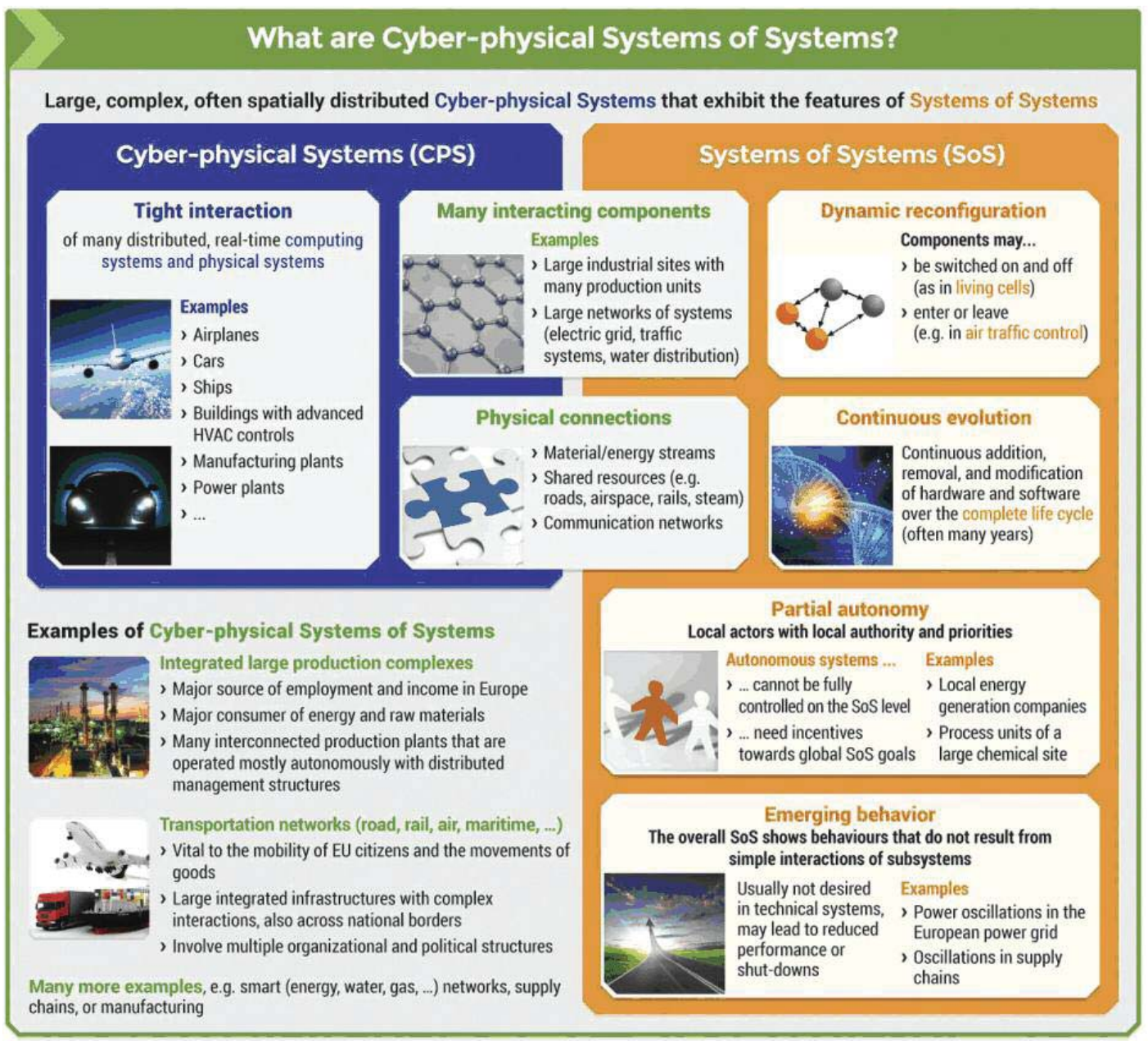

Figure 1: Explanation of Cyber-Physical Systems of Systems, from [3].

agement structures, the control and management tasks in such systems cannot be performed in a centralized or hierarchical top-down manner with one authority tightly controlling all subsystems. In CPSoS, there is a significant distribution of authority with partial local autonomy [3]. The design of such management systems for reliable and efficient management of the overall systems poses a key challenge in the design and operation of CPSoS.

The following sub-topics should be addressed:

- Decision structures and system architectures,

- Self-organization, structure formation, and emergent behaviour in technical systems of systems,

- Real-time monitoring, exception handling, fault detection and mitigation of faults and degradation,

- Adaptation and integration of new components,

- Humans in the loop and collaborative decision making,

- Trust in large distributed systems.
Challenge 2: Engineering support for the design-operation continuum of Cyber-Physical Systems of Systems While model-based design methods and tools have been established in recent years in industrial practice for traditional embedded systems, the engineering of CPSoS poses key challenges that go beyond the capabilities of existing methodologies and tools for design, engineering, and validation. These challenges result directly from the constitutive properties of CPSoS, such as their process of continuous evolution and the high degree of heterogeneity and partial autonomy of CPSoS.

The efficient design and operation of such systems requires new design support methodologies and software tools in the following areas:

- Integrated engineering of CPSoS over their full life-cycle,

- Modelling, simulation, and optimization of CPSoS, and

- Establishing system-wide and key properties of CPSoS.
Challenge 3: Cognitive Cyber-Physical Systems of Systems

SoSs by their very nature are large, distributed and extremely complex, presenting a myriad of operational challenges. To cope with these challenges there is a need for improved situational awareness. Gaining an overview of the entire SoS is inherently complicated by the presence of decentralized management and control. The introduction of cognitive features to aid both operators and users of complex CPSoS is seen as a key requirement for the future to reduce the complexity management burden from increased interconnectivity and the data deluge presented by increasing levels of data acquisition. Research in a number of supporting areas is required to allow vertical integration from the sensor level to supporting algorithms for information extraction, decision support, automated and selflearning control, dynamic reconfiguration features and consideration of the sociotechnical interactions with operators and users. 
The following subtopics have been identified as being necessary to support a move to Cognitive CPSoS:

- Situation awareness in large distributed systems with decentralized management and control,

- Handling large amounts of data in real time to monitor the system performance and to detect faults and degradation,

- Learning good operation patterns from past examples, auto-reconfiguration and adaptation,

- Analysis of user behaviour and detection of needs and anomalies.

A public consultation process on the roadmap was undertaken in April-June 2015 (results: http://www.cpsos.eu/ public-consultation/).
The research topics listed above provide a strategic long-range research agenda. The working groups of CPSoS will complement this strategic research agenda by sector-specific medium-term research and innovation topics that should be tackled by cooperative research projects in the near future.

Further information will be provided in the CPSoS newsletter which is available via http://www.cpsos.eu/news-events/ news/.

The CPSoS project has received funding from the European Union Seventh Framework Programme (FP7/20072013) under grant agreement $n^{\circ} 611115$.

Link: http://www.cpsos.eu
References:

[1] M. A. Reniers, Sebastian Engell: "A

European Roadmap on Cyber-Physical

Systems of Systems", ERCIM News

2014 (97), 2014.

[2] R. Boagey: “Automotive Cyberphysical systems: the next computing revolution", Automotive Megatrends, Q3, pages 104-106, 2014.

[3] S. Engell, J. Lygeros,

S.Grammatico: "The emergence of

systems of systems", Pan European

Networks: Science \& Technology, Vol

14, pages 79-81, 2015,

http://www.paneuropeannetworkspublic ations.com/ST14/\#78

Please contact:

Michel Reniers, TU/e, The Netherlands

E-mail: m.a.reniers@TUE.nl

\title{
GT SoS: Research Network on Trustworthy Software-intensive Systems-of-Systems
}

\author{
by Flavio Oquendo, Axel Legay and Khalil Drira
}

This French initiative in the framework of the CNRS GDR GPL establishes an open research network for tackling the emerging domain of software-intensive systems-of-systems. It focuses on bringing together researchers and practitioners, in a national effort, to discuss and enable the development of novel and sound theories, languages, methods, processes, and tools for architecting and engineering trustworthy software-intensive systems-of-systems.

Since the dawn of computing, the complexity of software and the complexity of systems reliant on software have grown at a staggering rate. In particular, software-intensive systems have rapidly evolved from being stand-alone systems in the past, to be part of networked systems in the present, to increasingly become systems of systems in the future.

With networks becoming increasingly pervasive, it is now possible to interconnect systems that were independently developed, operated, managed, and evolved, yielding a new kind of complex system, i.e. a system that is itself composed of systems, the 'System-of-Systems' (SoS). SoSs are evolutionarily developed from systems to achieve missions that cannot be achieved by a system alone.

Trustworthy SoSs are of paramount necessity since various aspects of our lives and livelihoods are becoming progressively dependent on some sort of SoS. SoSs are relied upon in areas as diverse as aeronautics, the automotive industry, energy, healthcare, manufacturing, and transportation; and applications that address societal needs, such as environmental monitoring, emergency coordination, traffic control, smart grids, and smart cities.

Complexity is intrinsically tied to SoSs, since SoSs by definition result in emergent behaviour: missions are achieved in SoSs through emergent behaviour drawn from the local interaction among constituent systems.

Therefore, the endeavor of conceiving and constructing trustworthy systems has evolved from engineering complicated systems in the last century, to architecting trustworthy SoSs in this century [1]. Trustworthy SoSs, by their very nature, have intrinsic properties that are hard to address.

Indeed, trustworthiness is a holistic property that calls for the co-engineering of safety and cyber-security, among other qualities. It is not sufficient to address one of these attributes in isolation, nor is it sufficient simply to assemble constituent systems that are themselves trustworthy (composing trustworthy constituent systems may imply an untrustworthy SoS). Integrating the constituent systems and understanding how the trustworthiness dimensions interact as well as how these interactions create emergent behaviour influencing safety and security is a central issue in architecting a trustworthy SoS.

A grand research challenge is presented by the unique characteristics of SoSs, namely: the operational and managerial independence of their constituent systems, as well as their geographic distribution (they are not all in one place), and the evolutionary development and emergent behaviours that emerge.

Additionally, the environment in which an SoS operates is only partially known at design-time, i.e. it is too unpre- 